\title{
Biosurfactants Production by Fermentation Process Using Waste as Substrate - A Patent Search Report
}

\author{
Ana Verena Pimentel Leal de Moraes Rego ${ }^{*}$, Márcio Costa Pinto da Silva ${ }^{2}$, \\ Edna de Almeida Santos ${ }^{2}$, Érika Durão Vieira ${ }^{2}$ \\ ${ }^{1}$ Federal University of Bahia; ${ }^{2}$ Integrated Center for Manufacturing and Technology, ${ }^{2}$ SENAI CIMATEC University Center; \\ Salvador, Bahia, Brazil
}

\begin{abstract}
Biosurfactants are active compounds capable of reducing surface tensions produced by microorganisms, having low toxicity and high biodegradability with possible production from renewable sources. This work aims at presenting a patents search on the biosurfactants production through fermentation, using waste as substrate. The methodology consisted of searching keywords and their blending, using the database of Derwent innovation. The search returned 15 patent registrations filed in the last 8 years. Of the 15, 10 orders are active. After analysis, 3 of the 10 selected patents showed strong adherence to the subject, describing the use of waste as substrates to produce more economical biosurfactants.
\end{abstract}

Keywords: Patents. Substrate. Fermentation. Waste. Biosurfactant.

\section{Introduction}

Biosurfactants are substances synthesized by microorganisms and have amphipathic properties, containing a hydrophilic and a hydrophobic part. They are active compounds with the capacity to reduce surface tension, low toxicity, biodegradable, and from renewable sources productions [1]. Due to the advantage of being more biodegradable when compared to surfactants of chemical origin, they are more appropriate to be used in various applications, such as bioremediation and dispersion in oil spillage; improved oil recovery; removal of oil residues in storage tanks; herbicide, and pesticide formulations; pharmaceutical and cosmetic application [2,3].

However, the production of biosurfactants is limited due to their high cost, low productivity, and the use of expensive substrates. Metabolites produced from cheap, renewable substrates and through economically feasible processes decrease the production costs of biosurfactants [1].

Received on 15 June 2021; revised 25 August 2021.

Address for correspondence: Ana Verena Pimentel Leal de Moraes Rego. Av. Orlando Gomes, 1845 - Piatã, Salvador BA- Brazil. Zipcode: 41650-010. E-mail: anaverena.com@ gmail.com.

J Bioeng. Tech. Appl. Health

2021;4(3):100-104

(C) 2021 by SENAI CIMATEC. All rights reserved.
Thus, the economic viability of biosurfactant production at the industrial level is linkage to the cost of the substrate. In this sense, the use of waste or industrial by-products represents an excellent alternative for reducing production costs, especially if this waste has many sources of carbon, which is the principal metabolite for the growth of microorganisms [4].

So, patent research is necessary because it is from it that it is possible to detect technological trends and which regions invest most in each area, which in this article is the production of biosurfactants by fermentation from waste as substrates, thus allowing the identification of relevant technologies, partners, innovations, and investments. And it is from this those patents can help the search for new methodologies and techniques in the production of biosurfactants by economically viable substrates.

\section{Patent}

The patent is legal protection over an industrialized invention or creation. It gives the sole right of the inventor or assignee to prevent others from using without his consent. This exclusivity depends on the presentation of documents describing the invention and proving its use [5].

Patents are granted by the State, in which in Brazil, the responsible agency is the National Institute of Industrial Property (INPI). They are granted 
throughout the national territory, with temporary terms depending on the type of patent $[5,6]$. So, for creation or invention to be patented, it must be either an invention patent, valid for 20 years, that is granted to a technological good that meets the requirements of novelty, inventive step, and industrial application, or a utility model patent, which is conferred on an object of practical use or part of it, is susceptible to industrial application, has a new form and results in a functional improvement of the object, and its validity is 15 years $[5,6]$. Thus, patents are the instrument for the author or inventor to protect, as a legal right to his invention or industrialize creation [6]. In this context, the objective of this study was to search and evaluate patents related to the production of biosurfactants by a fermentation process using waste as substrates at the Derwent innovation database from Clarivate Analytics.

\section{Materials and Methods}

The informational research happened between July 7 and 13, 2021, on Derwent Innovation database from Clarivate Analytics. The search strategy used was the combination of keywords in the field SMART TOPIC, comprehending title, abstract, and keywords, with words previously chosen due to researching patents related to the object of study: production of biosurfactant by bacillus fermentation, using waste as substrate.

Table 1 shows the keywords chosen, and their synonyms or similar technical terms sorted in the columns. The search was carried out in all the languages available in the database, with the word appearing, without restriction, anywhere in the text from 2012 to 2020.
We analyzed the results and the registers with had relevance for the proposed theme were selected.

\section{Results and Discussion}

The search resulted in 15 patents registers in the DWII database. After the analysis, we selected 10 relevant patents. Some refer to the use of waste as substrates, and other patents regard the applicability of biosurfactants. Figure 1 shows the patent publishing trends of the 15 relevant patents application selected from 2012 to 2020 . We observed that in 2020, 7 patents were registered, that is, half of the 15 patents in the 8 years, demonstrating that the production of biosurfactants through fermentation processes is a very recent technology developed in the last 10 years.

The results were sorted by region and country, and we noticed that China leads the publication of patents in this theme. Brazil presents the registration of one patent.

The main assignees of the patents and their inventors are mostly Chinese groups (Figures 3 and 4). Since there are more than 15 patents filed, we highlight that assignees and top inventors participate in more than one patent.

Among the 15 patents presented, 10 are active and 3 of them point to adherence to the proposed theme, which is the production of biosurfactants from waste as substrates. Among the 3 active patents with strong adherence to the theme, one of them: "Spore strain and application" uses urban waste as a carbon source to produce biosurfactants. This patent concerns a strain of spores that can use urban waste as a carbon source to produce biological

Table 1. Keywords used in the search.

\begin{tabular}{lllll}
\hline \multicolumn{3}{c}{ Synonyms } & & \\
\hline Product & Biosurfactant & & & \\
Feedstock & Residue & Waste & Bagasse & Lee \\
Process & Fermentation & & & \\
Biocatalyst & Bacillus & & & \\
\hline
\end{tabular}


Figure 1. Patents registered.

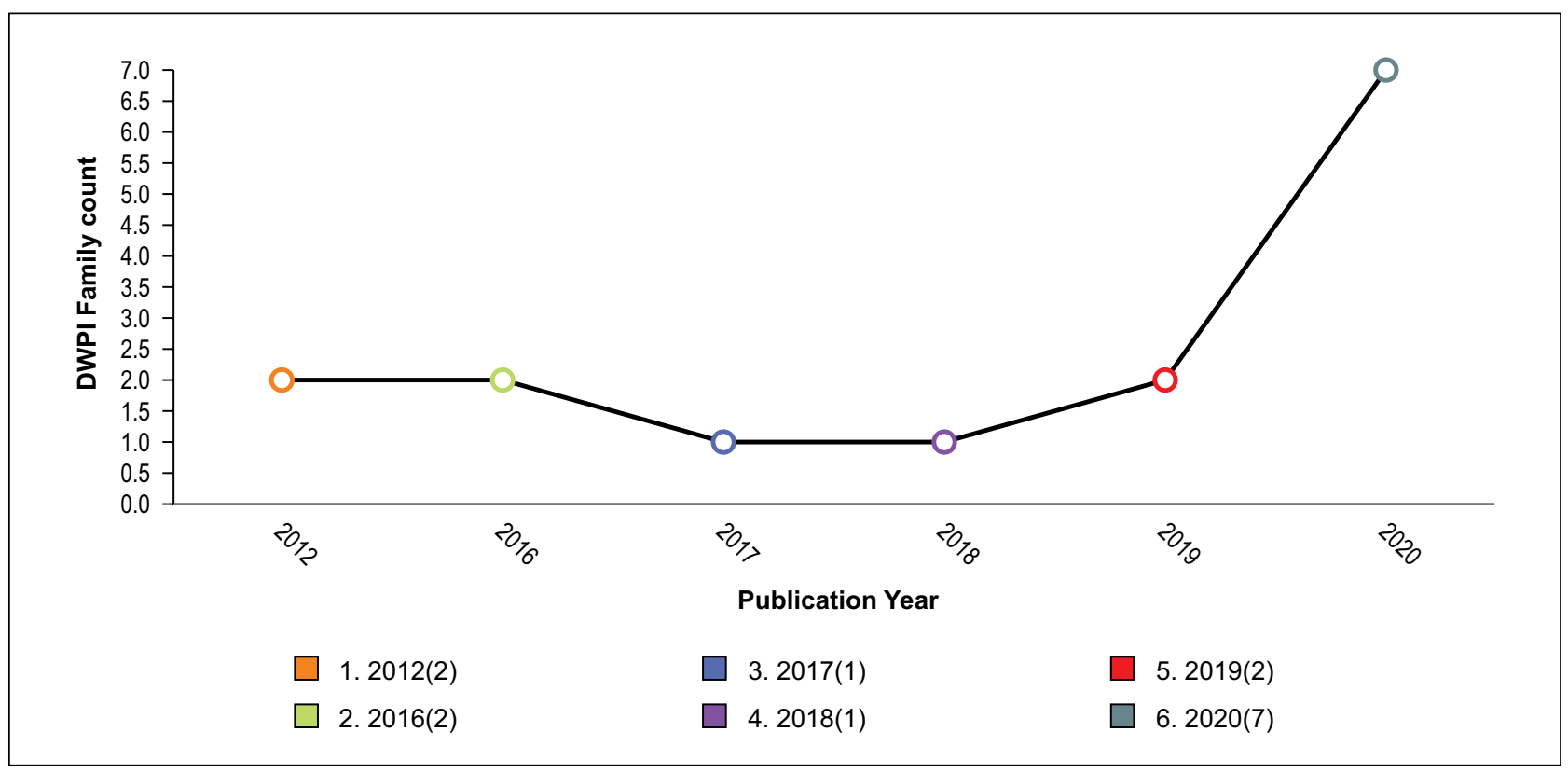

Figure 2. Patents registered by the country.

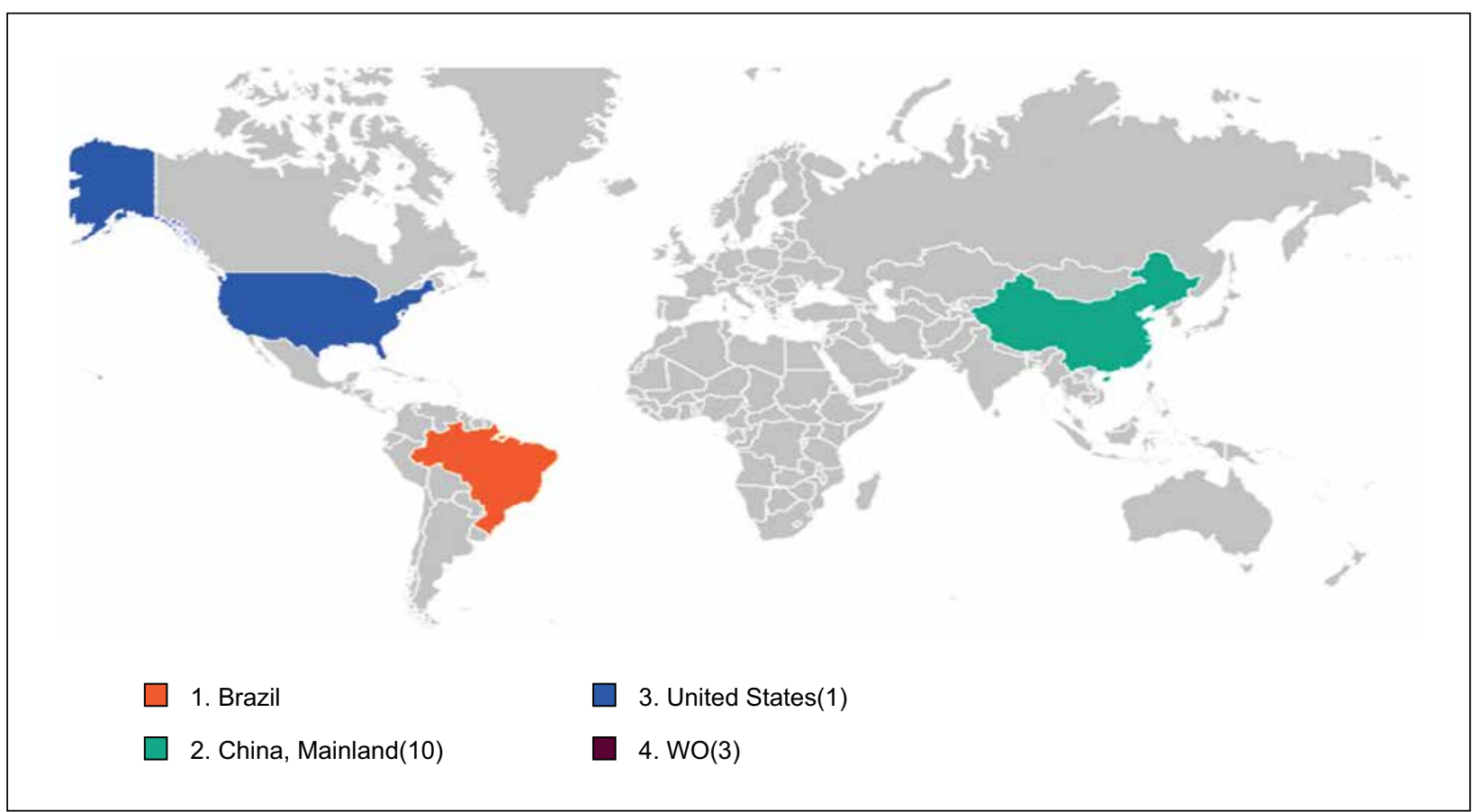


Figure 3. Top Assignees (created 2021-07-13).

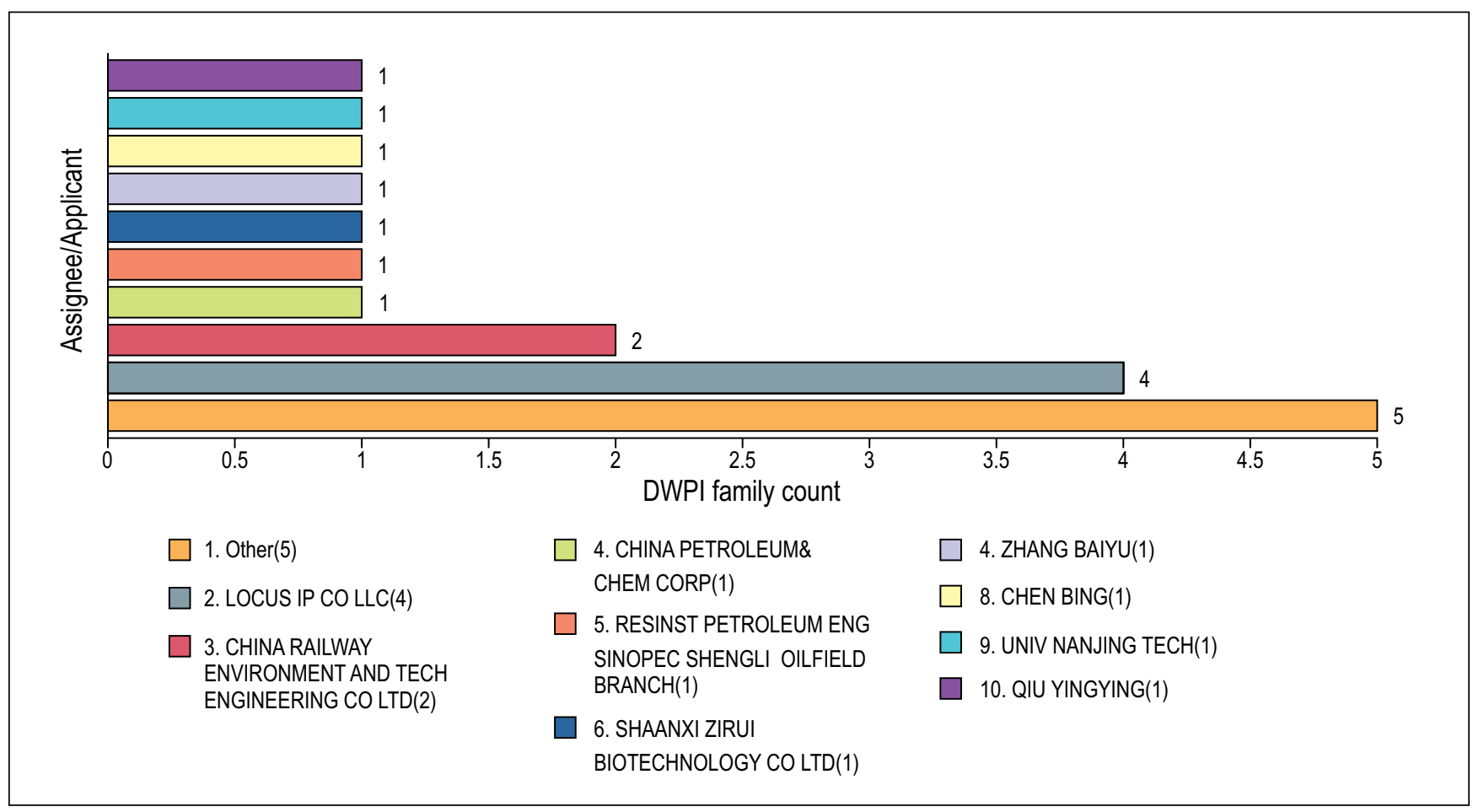

Figure 4. Top Inventors (created 2021-07-13).

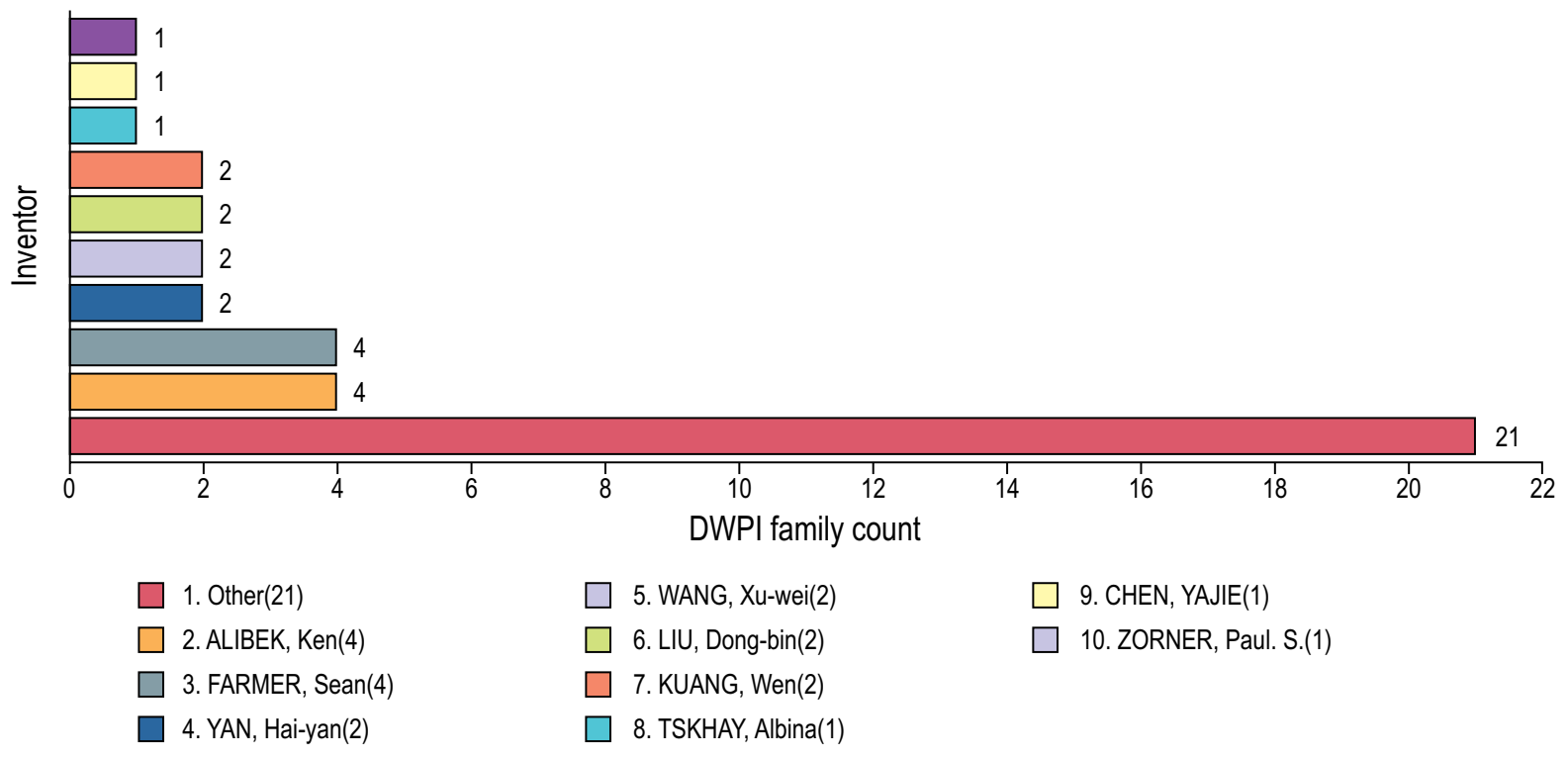


surfactants. These crops can promote the growth of tomatoes and corn, exhibiting an adjustment effect and a fertilizing effect. In addition, the invention also claims a new technique for preparing biological surfactant, using urban waste as a carbon source, reducing production costs, and recycling waste.

The second patent: "A method for preparing biosurfactant by fermentation of aquatic product waste" uses aquatic waste, more specifically, fish waste for producing biosurfactants. The method of preparing biosurfactants by fermentation of aquatic waste consists of adding water and hydrological protease to fish residues and thus undergoing hydrolysis to obtain the fish wastewater solution. Subsequently, centrifugation is made, followed by extraction of the supernatant and it is freezing so that lyophilization can be done to obtain fish peptide. After that, the seed culture medium is prepared, the fermentation medium using peptone, and the extraction of biosurfactant. This production from the fermentation of fish waste prevents environmental pollution and increases the yield of the biosurfactants produced when compared to other biosurfactants produced by traditional methods.

Finally, the third patent with adherence to the theme was "Preparing method of lipopeptide biosurfactant" using xylose, an agricultural residue as a substrate to produce biosurfactants. The biosurfactant thrives method involves incubating the G-34 cell of Bacillus subtilis and the culture medium understands xylose as the central source of carbon. In addition to xylose as a carbon source, there is the acid hydrolysate of corn cob and corn straw or agricultural by-products. We also used the source of nitrogen for fermentation, which is a cheap biomass residue such as hydrolyzed feather residues or a solution of monosodium glutamate fermentation residues. The fermentation culture medium also includes the acetic acid addition to promote the fermentation of the strain to prepare the biosurfactant. Thus, with the use of this agricultural residue, there is a reduction in the cost of production of lipopeptide biosurfactants.

Thus, these patents show alignment with the proposed theme. The other 7 patents mention areas with great potential for biosurfactants applications. The patent entitled "A preparation method of degrading kitchen waste processing" makes an analogy to the preparation of degrading bacteria containing in its composition biosurfactant - for the treatment of food waste.

\section{Conclusion}

The search resulted in 15 relevant patent documents related to biosurfactant production and its applicability. The patents were published between 2012 and 2020. The participation of the Chinese is relevant. Among the 10 patents selected, 3 mentioned the need for biosurfactants production from economically viable substrates to reduce production costs. Based on the patents presented, to reduce production costs, it is necessary to use economical substrates. And also, 7 patents demonstrated that biosurfactants have economic, environmental, and industrial applicability. It ratifies the need to reduce the costs of their production.

\section{Acknowledgments}

We thank PIBIC CNPq, grant number 103739, for the financial support of the project.

\section{References}

1. Bezerra MS. Estudo da Produção de biossurfactante sintetizados por Pseudomonas aeruginosa AP029GVIIA utilizando manipueira como fonte de carbono, UFRN, 2012.

2. Nitschke $\mathbf{M}$, et al. Structure, and applications of a rhamnolipid surfactant produced in soybean oil waste. Applied Biochemistry and Biotechnology, 2010.

3. Pirôllo MPS. Estudo da produção de biossurfactante utilizando hidrocarboneto. Dissertação de Mestrado, UNESP, 2006.

4. Nitschke M, et al. Oil wastes as unconventional substrates for rhamnolipid biosurfactant production by Pseudomonas aeruginosa LBI. Biotechnology Progress, 2005.

5. Oliveira LG, et al. Informações patentes: ferramenta indispensável para a pesquisa e o desenvolvimento tecnológico. Química Nova 2005;28(suppl).

6. Brasil. Instituto Nacional da Propriedade Industrial. Patentes. 13 de maio de 2020. 